\title{
Maternal and perinatal outcome in hypothyroidism in pregnancy: a prospective observational study
}

\author{
Deepika Sharma*, Pratibha V. Dixit, Yogita Gavit
}

Department of Obstetrics and Gynecology, Government Medical College, Aurangabad, Maharashtra, India

Received: 07 October 2017

Accepted: 04 November 2017

\section{*Correspondence:}

Dr. Deepika Sharma,

E-mail: drdeepikasharma03@gmail.com

Copyright: (C) the author(s), publisher and licensee Medip Academy. This is an open-access article distributed under the terms of the Creative Commons Attribution Non-Commercial License, which permits unrestricted non-commercial use, distribution, and reproduction in any medium, provided the original work is properly cited.

\begin{abstract}
Background: This study was conducted to analyse the antenatal complications, perinatal outcome and to be advocate routine screening for thyroid disorders in pregnancy. This study was prospective and observational study with 50 cases which was newly diagnosed when suspected as pregnancy with thyroid disorders. The commonest thyroid disorder found in pregnancy is hypothyroidism and it adversely affects the maternal and fetal health in the form of infertility, early pregnancy loss, PIH, anaemia, IUGR, PROM, preterm labor, neonatal and maternal morbidity and mortality. If thyroid disorders are appropriately detected and treated either before or in early pregnancy, the adverse maternal and fetal outcome can be prevented.

Methods: The present study was conducted in a tertiary care centre Mumbai from June 2015 to October 2016. All pregnant females who are newly diagnosed as hypothyroid, attending the ANC clinic were enrolled in the study.

Results: In the present study, most common obstetric complication observed was preeclampsia and most common fetal complication was preterm delivery.

Conclusions: In view of the high prevalence of thyroid dysfunctions in Indian pregnant woman and its association with different adverse pregnancy related complications we recommend routine screening for thyroid dysfunctions in pregnancy.
\end{abstract}

Keywords: IUGR, Preeclampsia, PROM, Thyroid function

\section{INTRODUCTION}

The most frequent thyroid disorder in pregnancy is maternal hypothyroidism. There is a wide geographic variation in prevalence of hypothyroidism during pregnancy. It varies from $2.5 \%$ from the west to $11 \%$ from India. ${ }^{1}$ Prevalence of hypothyroidism was found to be more in Asian countries compared with the western countries. Untreated or inadequately treated and subclinical hypothyroidism all are associated with increased risk of miscarriage, preeclampsia, anaemia, fetal growth restriction, placental abruption, perinatal and neonatal morbidity and mortality, preterm delivery, small head circumference, low birth weight impaired neuropsychological development. ${ }^{2}$

Untreated maternal overt hypothyroidism is associated with adverse neonatal outcomes including premature birth, low birth weight, and neonatal respiratory distress. There may be more fetal and perinatal death, and gestational hypertension may also contribute to the overall increase in neonatal risks. Since hypothyroidism is easily treated, timely detection and treatment of the disorder could reduce the burden of maternal and perinatal outcome. The purpose of study was to prospectively evaluate and compare the maternal and 
perinatal outcome of pregnant women who were diagnosed during pregnancy.

\section{METHODS}

The present study was conducted in a tertiary care center Mumbai from June 2015 to October 2016 after taking permission from institutional ethical committee. Cases were enrolled till June 2016 and the last case was followed up till October 2016.

\section{Inclusion criteria}

All pregnant females who are newly diagnosed as hypothyroid, attending the ANC clinic.

\section{Exclusion criteria}

- H/O Cardiac disease.

- H/O Bronchial asthma.

- H/O Hematological disorder

- Diabetic

- Liver disorders

\section{Patient selection}

- Patient selection will be according to ATA guidelines high risk screening recommendation

- Women with family H/o thyroid disease

- Women with type 1 diabetes, other autoimmune disorders like adrenal insufficiency, atrophic gastritis, pernicious anemia, systemic sclerosis, SLE, Sjogren's syndrome, hyperparathyroidism, vitiligo etc.

- Women with H/o either miscarriage or preterm delivery Women with infertility as a part of work up Women with prior therapeutic head or neck irradiation

- Women with morbid obesity.

Informed consent was obtained from each patient included in the study. Detailed clinical history including parity, obstetrical history was taken. All the routine investigations and thyroid profile estimation was carried out. If TSH was deranged (high, $>2.5 \mu \mathrm{U} / \mathrm{L}$ in $1^{\text {st }}$ trimester and $>3.0 \mu \mathrm{U} / \mathrm{L}$ in $2^{\text {nd }}$ and $3^{\text {rd }}$ trimester) then FT4 and FT3 levels were checked.

When TSH was increased and FT4 was decreased then it was overt hypothyroidism. It was diagnosed subclinical when FT4-normal, thyroxin was given in both types. Every 8 weeks TSH level was estimated and the dose of the drug adjusted. At the end, the obstetric outcome and perinatal outcome of the pregnancy was noted.

\section{Statistical analysis}

The data obtained was analyzed with SPSS version 20.0. The qualitative data was represented as frequency and percentage, bar diagram. Quantitative data was analyzed by mean, standard deviation. The association between two qualitative data was analyzed by chi-square test and $P$ value $<0.05$ was considered significant.

\section{RESULTS}

The present study was conducted at tertiary care centre, Mumbai from June 2015 to October 2016. Cases were enrolled till June 2016 and the last case was followed up till October 2016. The baseline characteristics of 50 patients who were included are shown in Table 1 . In the present study 32 cases (64\%) belongs to age group of 18 24 years followed by 18 (36\%) belongs to 25-30 years age group. Most of our population belongs to low socioeconomic status who conceive in early 20 's so mean age in the present study among subclinical is 24.38 years. and among overt cases is 24.4 years. comparable to Nidhi et al which was 26.7 years. ${ }^{3}$

Table 1: The distribution of patients based on parity index.

\begin{tabular}{|lll|}
\hline Parity & Frequency & Percent \\
\hline Primigravida & 21 & 42.0 \\
\hline Multigravida & 29 & 58.0 \\
\hline Total & 50 & 100.0 \\
\hline
\end{tabular}

Table 2: Distribution of study group as per gestational age at the time of diagnosis.

\begin{tabular}{|lllll|}
\hline \multirow{2}{*}{$1^{\text {st }}$ trimester } & number & 0 & Subclinical hypothyroidism & Total \\
\cline { 2 - 5 } & $\%$ & 0 & 0 & 0 \\
\multirow{2}{*}{$2^{\text {nd }}$ trimester } & number & 6 & 0 & 0 \\
\hline \multirow{2}{*}{$3^{\text {rd }}$ trimester } & $\%$ & $60 \%$ & 33 & 39 \\
\cline { 2 - 5 } & number & 4 & $72.5 \%$ & $78 \%$ \\
\hline \multirow{2}{*}{ Total } & $\%$ & $40 \%$ & $17.5 \%$ & $22 \%$ \\
\hline
\end{tabular}


In Table 1 total numbers of primigravidae patients are 21 and multigravida are 29 which is comparable to Dhara et al and Jyanti et al. ${ }^{4,5}$ Present study done in tertiary health centre where most population belongs to low socioeconomic class, these populations had multiple pregnancies, so majority of the present study cases are multigravida.

There is no significance between time of diagnosis and serum TSH level $(\mathrm{P}=0.197)$ As per Table 2, 78\% patient were diagnosed during second trimester and $22 \%$ were diagnosed during third trimester. Most cases were diagnosed in $2^{\text {nd }}$ trimester because most patients in our ANC OPD came for registration in the second trimester followed by third trimester.

In the present study total numbers of overt hypothyroid patients were $10(20 \%)$ and subclinical hypothyroidism was $40(80 \%)$. This is because of much higher incidence of subclinical hypothyroidism than overt hypothyroidism which is comparable with Abalovich et al. ${ }^{6}$ Mean serum TSH level at the time of diagnosis among subclinical hypothyroid patient is 3.73 and among overt hypothyroid patient is 13.40 which is significantly very high $(\mathrm{p}=0.0001)$ as compared to subclinical. It is comparable to Nidhi et al where it was 5.2 mIU. $^{3}$

Table 3: Distribution of patients on the basis of serum TSH level at the time of diagnosis.

\begin{tabular}{|lll|}
\hline $\begin{array}{l}\text { Serum TSH level at } \\
\text { time of diagnosis }\end{array}$ & Frequency & Percent \\
\hline Overt & 10 & 20.0 \\
\hline Subclinical & 40 & 80.0 \\
\hline Total & 50 & 100.0 \\
\hline
\end{tabular}

Most common complication seen was preeclampsia which was seen in $33.3 \%$ cases in both subclinical and overt hypothyroidism followed by gestational diabetes and preterm which was seen in $23.8 \%$ cases each. Eclampsia, IUGR and oligohydramnios were seen in few cases. It is comparable to Dhara et al and Jyanti et al where preeclampsia was the most common complication noted. ${ }^{4,5}$ In study done by Manjunath et al in Karnataka, shows significant increase in the TSH levels in preeclampsia than in normal pregnancy. ${ }^{7}$ Therefore, thyroid disorder is one of the predisposing causes for preeclampsia.
Figure 1 shows comparison between maternal complication among subclinical and overt hypothyroid patients. As shown in the above graph $20 \%$ cases of subclinical hypothyroidism had preterm delivery whereas $33.3 \%$ of overt hypothyroidism had preterm delivery. In addition to this occurrence of preeclampsia is equal in both overt and subclinical i.e. $33.3 \%$, gestational diabetes was seen in $26.6 \%$ cases in subclinical cases whereas among overt it is seen in $16.7 \%$.

Oligohydramnios was seen in $6.6 \%$ of subclinical cases but was not seen in overt cases, $6.6 \%$ patients had IUGR among subclinical cases but same was not seen in overt cases which is comparable to Tanuja et al and Jyanti et al where more complication were seen in overt than subclinical cases. ${ }^{5,8}$

In this study 50 hypothyroid cases were studied and among them 26 delivered vaginally and 13 underwent caesarean section which is comparable to Nidhi et al who had more vaginal delivery than LSCS but among studies like Dhara et al and Mahendra et al LSCS rate is more than vaginal delivery. $3,4,9$

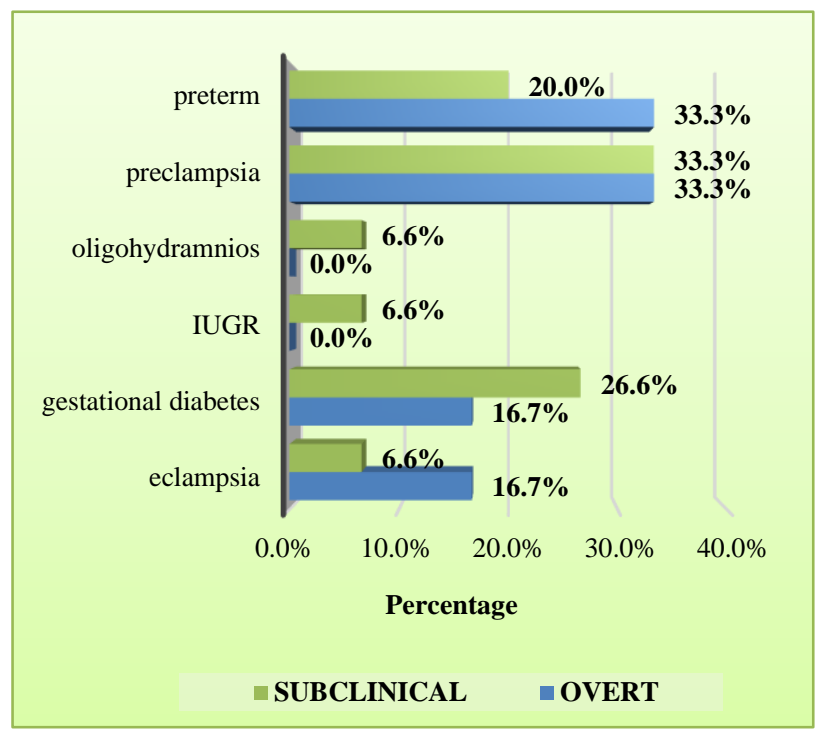

Figure 1: Distribution of cases as per maternal complications.

Relation between serum TSH level and mode of delivery not significant $(\mathrm{p}=0.707)$.

Table 4: Distribution of study group on the basis of gestational age at the time of delivery.

\begin{tabular}{|c|c|c|c|c|}
\hline \multicolumn{2}{|c|}{ Gestational age at delivery } & Overt hypothyroidism & Subclinical hypothyroidism & Total \\
\hline \multirow{2}{*}{$<37$ weeks } & number & 4 & 18 & 22 \\
\hline & $\%$ & $40 \%$ & $45 \%$ & $44 \%$ \\
\hline \multirow{2}{*}{ > 37 weeks } & number & 6 & 22 & 28 \\
\hline & $\%$ & $60 \%$ & $55 \%$ & $56 \%$ \\
\hline \multirow{2}{*}{ Total } & number & 10 & 40 & 50 \\
\hline & $\%$ & $100 \%$ & $100 \%$ & $100 \%$ \\
\hline
\end{tabular}


As shown in Table 4, 28 patients were delivered at term among them 6 were overt and 22 were subclinical hypothyroid, while 22 had preterm delivery. Among them 4 were overt and 18 were subclinical but none of the patient was delivered post term. In the present study preterm delivery rate was $44 \%$ which is much higher as compared to Patwari $\mathrm{M}$ et al and Abalovich et al where preterm delivery rate was $19.4 \%$ and $20 \%$ respectively.., 6 Also no significant result was noted ( $p$ value 1 ) in relation to serum TSH level and preterm delivery. In study done by Chen et al found correlation between $\mathrm{SCH}$ and PROM which leads to preterm delivery. ${ }^{10}$

Table 5: Distribution of study group as per birth weight.

\begin{tabular}{lllll}
\multirow{2}{*}{ Birth weight } & & Overt hypothyroidism & Subclinical hypothyroidism & Total \\
\multirow{2}{*}{ LBW } & no. & 5 & 15 & 20 \\
\cline { 2 - 6 } & $\%$ & $50 \%$ & $37.5 \%$ & $40 \%$ \\
\multirow{2}{*}{ Normal } & no. & 5 & 25 & 30 \\
\cline { 2 - 6 } & $\%$ & $50 \%$ & $62.5 \%$ & $60 \%$ \\
\multirow{2}{*}{ Total } & no. & 10 & 40 & 50 \\
& $\%$ & $100 \%$ & $100 \%$ & $100 \%$ \\
\hline
\end{tabular}

As shown in Table 5 total number of cases having low birth weight were 20 i.e. (40\%) of which 5 were overt $(50 \%)$ and 15 were subclinical $(37.5 \%)$. No significant relation was noted between serum TSH level at the time of diagnosis and birth weight ( $p$ value $=0.492$ ) which is comparable to Dhara, Jyanti and Nidhi et al where low birth weight was seen in $13.26 \%, 24 \%$ and $29.73 \%$ cases respectively. ${ }^{3-5}$ Low birth weight was seen secondarily to either preterm delivery or IUGR. Correlation between preterm and hypothyroidism was seen in many studies, but no separate study done to see effect of hypothyroidism over IUGR.

Ten babies $(20 \%)$ of hypothyroid patients had APGAR score $<6$ whereas 40 babies $(80 \%)$ had APGAR score $>6$ which is much less as compared to Jyanti and Mahendra et al, in their studies babies having APGAR $<6$ at 1 minute were $46.6 \%$ and $30.64 \%$ respectively.

Table 6: Distribution of patients as per indication for NICU admissions.

\begin{tabular}{|lll|}
\hline $\begin{array}{l}\text { Indication for NICU } \\
\text { admission }\end{array}$ & Frequency & Percent \\
\hline Preterm & 7 & 33.3 \\
\hline Blood glucose monitoring & 5 & 23.8 \\
\hline IUGR & 5 & 23.5 \\
\hline Thick MSAF & 2 & 9.5 \\
\hline Hyperbilirubinemia & 1 & 4.8 \\
\hline Respiratory distress & 1 & 4.8 \\
\hline Total & 21 & 100.0 \\
\hline
\end{tabular}

Among 50 cases of hypothyroid patient 21 babies i.e. (42\%) got admitted to NICU after delivery which is comparable to Jyanti et al where it was $62.2 \%$ but higher than Nidhi et al. ${ }^{3,5}$ Most common reason for NICU admissions was Prematurity i.e. 7 Babies (33.3\%) followed by IUGR seen in 5 babies $(23.8 \%)$ and 5 babies were admitted for blood glucose monitoring. Similar result found in Jyanti et al, while in Nidhi et al NICU admission was $5 \%$. $^{3,5}$

In the present study we evaluated new-born TSH, FT3, FT4 levels, which were estimated after 72 hours of birth in all babies whose mother had thyroid dysfunction. It was found that TSH and FT3, FT4 levels in all these babies were within normal limit probably because we had treated these mothers for thyroid dysfunctions. The mean TSH level in neonates of patients with subclinical hypothyroidism was $4.80 \mathrm{~m} \mathrm{IU} / \mathrm{ml}$ whereas in overt hypothyroidism mean TSH was $4.89 \mathrm{~m} \mathrm{IU} / \mathrm{ml}$.

Table 7: Mean TSH levels among neonates in different thyroid disorders.

\begin{tabular}{|ll|}
\hline Babies serum TSH level & Mean TSH level \\
\hline Subclinical Hypothyroid & 4.8 \\
\hline Overt Hypothyroid & 4.89
\end{tabular}

\section{DISCUSSION}

The present study was done in a tertiary care centre, Mumbai. The study was performed to gain insight into the impacts of $\mathrm{SCH}$ and overt hypothyroidism on maternal and perinatal outcomes.

In the present study 50 newly diagnosed cases were studied. Mean age among subclinical cases is 24.38 years and among overt hypothyroid is 24.40 which is comparable to Nidhi et al. ${ }^{3}$ Mean gestational age is 36.78 weeks. Among SCH and among overt it is 36.6 weeks which is comparable to Dhara et al. ${ }^{4}$ Mean TSH level among subclinical hypothyroid patients was 3.73 and among overt hypothyroidism cases it was 13.40 which was significantly high ( $\mathrm{p}$ value $=0.0001$ ).

Among 50 patients, $20 \%$ patients develop complication during ANC or during labor in whom most common 
complications seen was preeclampsia i.e. $33.3 \%$ in both overt and subclinical hypothyroidism cases which was comparable to Dhara et al, Tanuja et al and Jyanti et al, but higher than Sahu et al. ${ }^{4,5,8,10}$ In study done by Manjunath et al to know association between preeclampsia and hypothyroidism, during their study there was no significant difference in T3 and T4 level in normal pregnancy and in preeclampsia but TSH level in preeclampsia patient was significantly increased.? Hypothyroidism cause vascular smooth muscle contraction both in systemic and renal vessels, which leads to increased diastolic pressure, peripheral vascular resistance, and decreased tissue perfusion which could be the pathophysiology of preeclampsia in hypothyroidism. ${ }^{12,13}$

Similarly, preterm was found in $20 \%$ cases of subclinical hypothyroidism and $33.3 \%$ in case of overt hypothyroidism which is comparable to Dhara et al and Nidhi et al but higher than Leung, Jyanti and Sahu et al. ${ }^{3,4,10,14}$ Chen et al compared euthyroid with $\mathrm{SCH}$ patient to study maternal outcome with respect to hypertensive disorders of pregnancy, GDM, PROM and preterm delivery. ${ }^{11}$ They concluded that pregnant women with $\mathrm{SCH}$ had increased risk of preeclampsia and PROM with significant $p$ value 0.002 which leads to preterm delivery.

In the present study total patients delivered vaginally are more than those delivered by caesarean section which is comparable to Nidhi et al but in Dhara et al more patients were delivered by caesarean section. ${ }^{3,4}$ In study by Dhara et al most common indication for higher caesarean delivery was bad obstetric history so they concluded the association of bad obstetric history with hypothyroidism, whereas no such conclusion can be drawn from the present study because most common indication in the present study was fetal distress or non-progress of labour in equal percentage.

In the present study total number of babies admitted in NICU were 21 i.e. (42\%). Similar results were found in Jyanti et al where NICU admission were $46.6 \%$ but in Nidhi et al only $13.5 \%$ babies were admitted to NICU. ${ }^{3}$ It might because percentage of all complication noted in the present study and Jyanti et al were higher than Nidhi et al.

\section{CONCLUSION}

Maternal hypothyroidism is a disorder with great potential to adversely affect maternal and fetal outcomes and is also associated with multiple other conditions which can affect maternal and fetal health. If the condition is detected early, it is easy to treat with very little detrimental effects to the mother and fetus. Hence, this condition needs early detection, prompt initiation of treatment, adequate follow-up and most importantly sufficient education of the doctors and the patients regarding these objectives and also they should be aware of importance of this condition along with ease and advantages of prompt management.

The Endocrine Society guidelines suggest that universal thyroid screening during pregnancy can't be recommended and aggressive case finding is recommended in specific subsets of subjects. ${ }^{12}$ The American Association of Clinical Endocrinologists recommends TSH measurement in women of childbearing age before pregnancy or during the first trimester. ${ }^{13}$ But recent studies have shown that targeted case finding will miss around $30-50 \%$ cases of hypothyroidism which is similar to the present study in which $62.5 \%$ of subclinical hypothyroid and $40 \%$ of overt hypothyroid patients did not have high-risk characteristics. These pregnant women could have been missed by targeted case finding.

\section{Recommendations}

In view of the high prevalence of thyroid dysfunctions in Indian pregnant woman and its association with different adverse pregnancy related complications we recommend routine screening for thyroid dysfunctions in pregnancy.

Funding: No funding sources

Conflict of interest: None declared

Ethical approval: The study was approved by the Institutional Ethics Committee

\section{REFERENCES}

1. Altomare M, La Vignera S, Asero P, Recupero D, Condorelli RA, Scollo P, et al. High prevalence of thyroid dysfunction in pregnant women. $\mathrm{J}$ Endocrinol Invest. 2013;36:407-11.

2. Unnikrishnan AG, Kalra S, Sahay RK, Bantwal G, John M, Tewari N. Prevalence of hypothyroidism in adults: an epidemiological study in eight cities of India. Ind J Endocrinol Metab. 2013;17:647-52.

3. Chauhan N, Nautiyal R. To study the profile of thyroid function in pregnancy and its correlation with the maternal and fetal outcome. Int J Biol Med Res. 2014;5(4):4565-8.

4. Dhara S, Bhati I, Bora S, Meena S. Study of thyroid dysfunction in pregnancy. Int J Curr Microbiol App Sci. 2015;4(9):91-7.

5. Nath J, Dutta S. A clinical study on thyroid dysfunction in pregnancy and its effect on the fetomaternal outcome. 2015;4(9):2068-70.

6. Abalovich M, Amino N, Barbour LA, Cobin RH, De Groot LJ, Glinoer D, et al. Management of thyroid dysfunction during pregnancy and postpartum: an endocrine society clinical practice guideline. J Clin Endocrinol Metab. 2007;92:S1-47.

7. Manjunath S, Basavraja GN, Patil RS. Thyroid dysfunction in pregnancy and preeclampsia. Sch $\mathbf{J}$ App Med Sci. 2014;2(6F):3297-9. 
8. Thanuja PM, Rajgopal K, Sadiqunnisa. Thyroid dysfunction in pregnancy and its maternal outcome. (IOSR-JDMS). 2014;13(1):11-15.

9. Patwari M, Talukdar B, Waanbah BD. Study of thyroid profile in pregnancy with perinatal outcome. New Indian J OBGYN. 2016;2(2):73-7.

10. Sahu MT, Das V, Mittal S, Agarwal A, Sahu M. Overt and subclinical thyroid dysfunction among Indian pregnant women and its maternal and foetal outcome. Obstet Gynaecol. 2010;281(2):215-20.

11. Chen LM, Du WJ, Dai J, Zhang Q, Si GX, Yang H, et al. Effects of subclinical hypothyroidism on maternal and perinatal outcomes during pregnancy: a single-center cohort study of a Chinese population. PloS One. 2014;9(10):e109364.

12. Alfadda A, Tamilia M. Preeclampsia-like syndrome that is associated with severe hypothyroidism in a 20-week pregnant woman. Am J Obstet Gynecol. 2004;191(5):1723-4.

13. Negro R, Mestman JH. Thyroid disease in pregnancy. Best Practice Research: Clinical Endocrinol Metabol. 2011;25(6):927-43.

14. Leung AS, Millar LK, Koonings PP, Montoro M, Mestman JH. Perinatal outcomes in hypothyroid pregnancies. Obstet Gynecol. 1993;81(3):349-53.

Cite this article as: Sharma D, Dixit PV, Gavit Y. Maternal and perinatal outcome in hypothyroidism in pregnancy: a prospective observational study. Int $\mathbf{J}$ Reprod Contracept Obstet Gynecol 2017;6:5548-53. 